\title{
Implementation of GLCM for Features Extraction and Selection of Batik Images
}

\author{
Dhimas Arief Dharmawan*1, Latifah Listyalina ${ }^{2}$ \\ ${ }^{1}$ Department of Electrical Engineering, Faculty of Engineering, Universitas Muhammadiyah Yogyakarta \\ Jalan Brawijaya, Geblangan, Tamantirto, Kasihan, Bantul 55183, Telp (0274) 387656 \\ ${ }^{21}$ Department of Electrical Engineering, Faculty of Scince and Technology, Universitas Respati Yogyakarta \\ JL. Laksda Adisucipto KM 6,3 Depok Sleman Yogyakarta 55281, Telp (0274) 488781 \\ *Corresponding author, e-mail: dhimasariefdharmawan@umy.ac.id
}

\begin{abstract}
Batik is a craft that has high artistic value and has been a part of Indonesian culture (especially Java) for a long time. Batik cloth in Indonesia has various types of batik textures, batik cloth colors, and batik fabric patterns that reflect the regional origins of the batik cloth. Regarding the image of batik, the texture feature is an important feature because the ornaments on the batik cloth can be seen as different texture compositions. Besides batik motifs, also influenced by the shape characteristics that become parts of each batik motif. This research will add insight and knowledge to understand batik patterns based on the characteristics of batik motifs, namely texture. There are five batik motifs used, namely inland solo batik, semarang coastal batik, sidhomukti batik, parangklithik batik, and sidhodrajat batik. Initially preprocessing is done by cropping and grayscalling. Of the five image motifs, a cropping process is carried out for each motif. The next step is feature extraction. The features of GLCM were selected in this study. From the features contained in the GLCM, in this study four features were chosen, namely contrast, energy, correlation, and homogeneity. The final step is the selection or selection of features. The result of the feature selection of the four features carried out feature extraction are energy and homogeneity.
\end{abstract}

Keywords: Batik images, features extraction and selection, GLCM

\section{Introduction}

The State of Indonesia is a country consisting of various islands, ethnicity, language and culture. False a culture that is characteristic Indonesia in the eyes of the world is batik. Batik is a culture Indonesia is almost just claimed by other countries, however at October 2, 2009 UNESCO has been recognize that batik is a right intellectual culture of the nation Indonesia [1]. Batik has a vast variety of motifs and colors. Aside from its popularity as being part of Indonesian culture, it has become the source of Indonesia's income. Batik has become the main part of national culture, however there is a lack of understanding for many people, as they are still unaware about batik motifs and patterns [2].

Batik motifs have vast variations, which is very difficult to identify for people. [3] aims to build an image search application of Yogyakarta's Batik Traditional Pattern based on the content of these images with texture feature extraction Filter Gabor Wavelets 2D. As the result of this research, this application has an accurate value to determine the appropriate images in the amount of $21,34 \%$ whereas the value of accuracy to take all the appropriate images in the amount of $39,63 \%$. The feature extraction process uses a combination of Gray Level Co-occurrence Matrix (GLCM) and statistical color RGB [4], A combination of Bag of Features (BOF) and Scale-Invariant Feature Transform (SIFT) [5], Discrete wavelet transform (DWT) [6]. Based on these previous works, researchers need to build the model identification of motifs using the method of back-propagation artificial neural network and template matching algorithm. 


\section{Theory Review}

\section{II.1 Batik}

Batik is an icon nation for Indonesia. Batik has awarded as cultural heritage from UNESCO on October 2nd, 2009 and it is significantly affected to batik industry afterward.The raising of batik industry caused some multiplier effects to economics and socio cultural in Indonesia[7]. In the current development of batik fabric patterns and textures are progressing so rapidly that there appears a wide variety of batik cloth that has a new texture or the texture of old batik cloth in the matching with the texture of batik cloth now so that it gets a new pattern of batik fabric texture (Imanuddin, 2010).
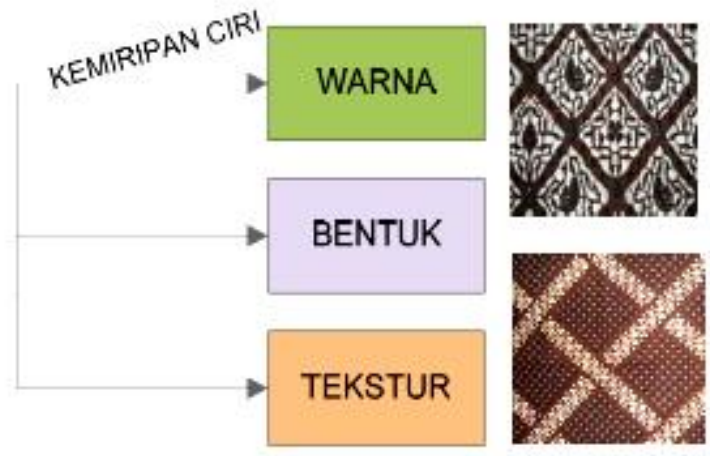

Figure 1. Characteristics of Batik Motifs Researched on Texture and Shape Characteristics (Rangkuti, 2014).

Images with different textures have different characteristics. Regarding the image of batik, the texture feature is an important feature because the ornaments on the batik cloth can be seen as different texture compositions. Besides batik motifs, also influenced by the shape characteristics that become parts of each batik motif. This research will add insight and knowledge to understand batik patterns based on the characteristics of batik motifs, namely texture. These characteristics are the basis for classification of images (Rangkuti, 2014)

\section{II.2 Feature Extraction}

Feature extraction with texture analysis is done by taking features from grayscale image in the form of entropy, contrast, energy, homogeneity, gray scale, and standard deviation, while feature extraction from a color image is a red color value $(\mathrm{R})$, green $(\mathrm{G})$, and blue (B) [9]. There are other features, namely GLCM GLCM itself stands for Gray Level Cooccurrence Matrix. The following equations are found in the GLCM features. (Riana, 2013).

1. Energi (Energy).

$$
f 1=\sum_{i} \sum_{j} p_{d}^{2}(i, j)
$$

2. Entropi (Entropy).

$$
f 2=-\sum_{i} \sum_{j} 2_{d}(i, j) \log \left(2_{d}(i, j)\right)
$$

3. Kontras (Contrast).

$$
f 3=\sum_{i} \sum_{j}(i-j)^{2} p_{d}(i, j)
$$

4. Homogenitas (Homogeneity).

$$
f 4=\sum_{i} \sum_{j} \frac{p_{d}(i, j)}{1+|i-j|}
$$

5. Korelasi (Correlation).

$$
f 5=\sum_{i} \sum_{j} \frac{\left(i-\mu_{x}\right)\left(j-u_{y}\right) p_{d}(i, j)}{\sigma_{x} \sigma_{y}}
$$

\section{II.3 Feature Selection}

Feature selection is one of the preprocessing stages which is especially useful in reducing data dimensions, eliminating irrelevant data, and increasing accuracy results (Yu and Liu 2003). Jain and Zongker (1997) define the problem of feature selection as follows: given a set of features then selected several features that are able to provide the best results in the classification.

There are two emphasis on feature selection with a machine learning approach according to Portiale (2002), namely selecting the features to be used and explaining conceptually how to combine these features to produce the correct induction concept or the appropriate result.

Feature selection is used to provide the characteristics of the data. Feature selection is one of the many studies conducted in various fields such as pattern recognition, process identification, and time series modeling.

\section{Methodology}

This research was compiled with the first stage of collecting the necessary data and then proceed with the design of the program until the final stage was 
the features of batik. The material from this study was taken from the Wikipedia website. There are five batik motifs used, namely inland solo batik, semarang coastal batik, sidhomukti batik, parangklithik batik, and sidhodrajat batik.

The first preprocessing step is done by cropping and grayscalling. Of the five image motifs, a cropping process is carried out for each motif. So we get 42 images of batik motifs, with details of 10 solo inland batik, 10 Semarang coastal batik, 6 sidhomukti batik, 8 parangklithik batik, and 8 sidhodrajat batik.

The results of the cropping process are done by grayscalling. The image that will be graded by the value of each point will be equated with the value of Red, Green, and Blue so that for each point only has 1 value called the graylevel value. The grayscaling process used takes a certain percentage of each color then is added to get a new value. Another way is to directly divide the three color values equally to get a new value (look for the average of the three color values of Red, Green, and Blue).

The next step is feature extraction. The features of GLCM were selected in this study. As a feature extraction method. From the features contained in GLCM, in this study four features were selected, namely contrast, energy, correlation, and homogeneity. Gray level Co-occurrence Matrix. GLCM generates a matrix value for each feature.

The final step is the selection or selection of features. This feature selection method is that each feature is calculated entropy on all images. Then the mean entropy calculation of the four features is performed for all images. Features with an entropy value less than the mean will be discarded and will not be used for the final feature.

\section{Result and Discussion}

The patterns of Batik used in this research are as follows.

\section{Batik Sidhodrajat}

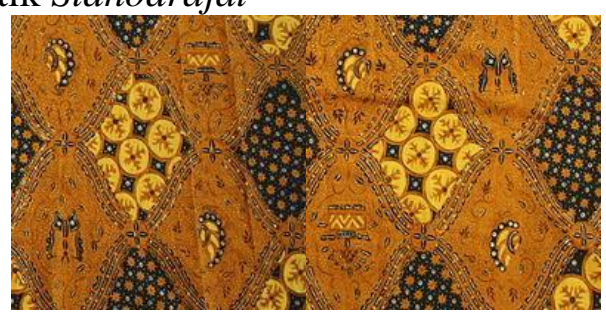

\section{Batik Parangklithik}

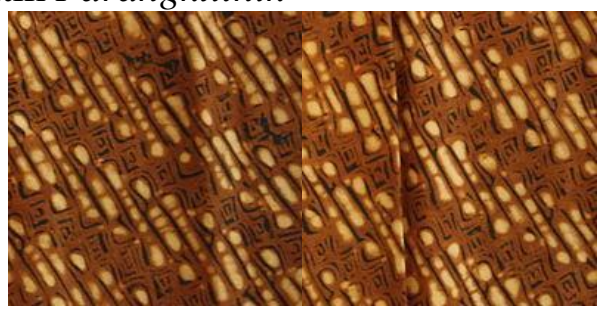

\section{Batik Sidhomukti}

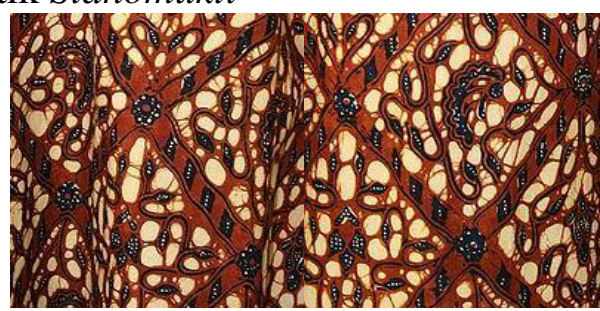

\section{Batik Pesisir Semarang}

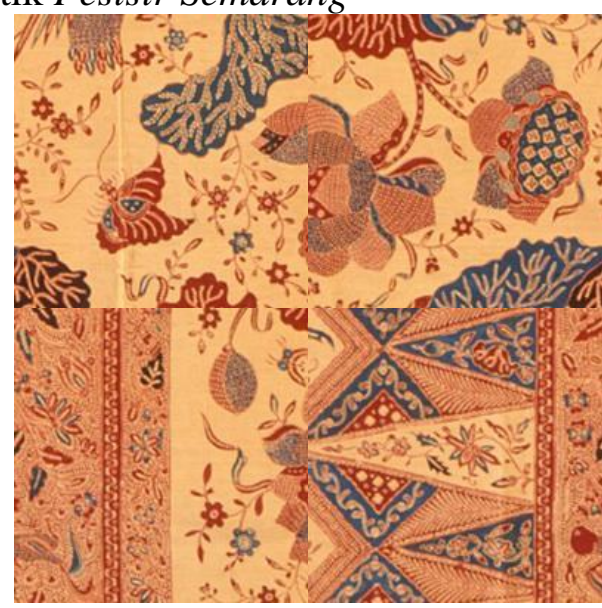

\section{Batik Pedalaman Solo}
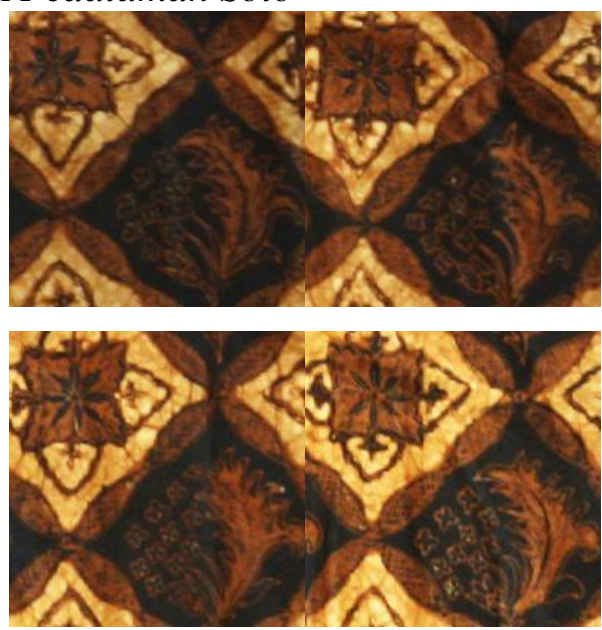


\section{a. Cropping}

Examples of images, batik inland solo image, before the cropping process is as follows.

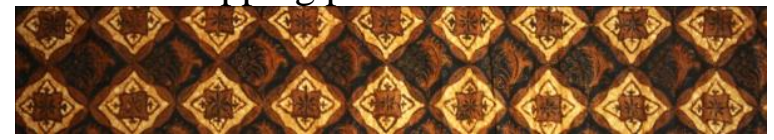

Examples of images, batik inland solo image, after the cropping process is as follows.

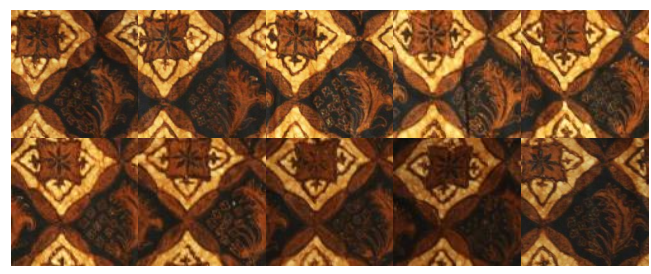

\section{b. Gray-scalling}

Examples of imagery, batik inland solo image, before the gray-scalling process is as follows

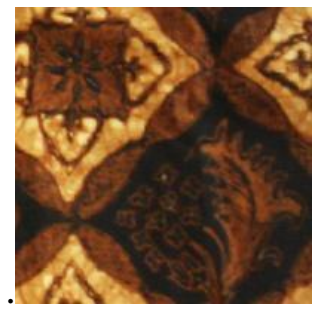

An example of an image, batik inland solo image, after the gray-scalling process is as follows.

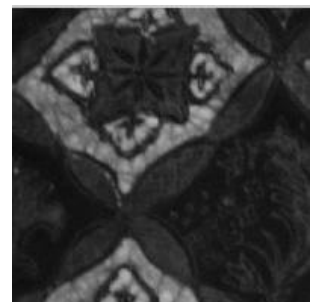

\section{c. Feature Extraction}

The results of feature extraction using GLCM are as follows.

$$
\begin{aligned}
& \mathrm{H}=4.0270 \quad 4.1039 \quad 4.2868 \quad 4.4406 \\
& \text { contrast energy correlation }
\end{aligned}
$$

\section{homogeneity}

\section{d. Feature Selection}

The results of feature selection using GLCM are as follows

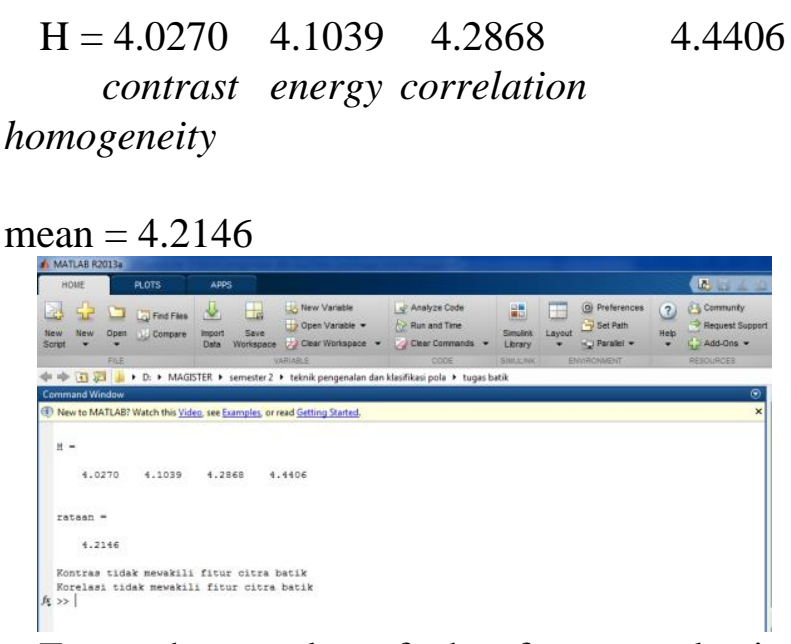

From the results of the feature selection process as shown above, the results obtained, namely contrast and correlation have entropy values less than the mean value of entropy. This means that the contrast and correlation do not represent the features of the batik image when compared with the other features above, namely energy and homogeneity.

\section{Conclusion}

The features chosen for feature extraction using GLCM are contrast, energy, correlation, and homogeneity. The results of the feature selection of the four features performed feature extraction are energy and homogeneity

\section{References}

[1] Bernardinus Arisandi, Nanik Suciati, and Arya Yudhi Wijaya (2011). "Pengenalan Motif Batik dengan Rotated Wavelet Filter dan Neural Network,".

[2] Suhartono, Sutikno and Priyo Sidik Sasongko (2017). "Modeling Identification of Batik Motif Using the Method of Back-propagation Artificial Neural Network and Template Matching Algorithm". Applied Mathematical Sciences, Vol. 11, 2017, no. 63, 3129 - 3139. University of Diponegoro Semarang, Indonesia.

[3] Alfonsus Stefan Arwanda (2009). Content Based Image Retrieval Batik Tradisional Yogyakarta Dengan Ekstrasi Ciri Berdasarkan Tekstur Filter Gabor Wavelets 2D. Universitas Sanata Dharma, Yogyakarta

[4] C. S. K. Aditya, M. Hani'ah, R. R. Bintana, N. Suciati, Batik classification using neural network with gray level co-occurrence matrix and statistical color feature extraction, Proceedings of 2015 
International Conference on Information and Communication Technology and Systems, ICTS, (2015), 163-168. https://doi.org/10.1109/icts.2015.7379892

[5] R. Azhar, Desmin Tuwohingide, Dasrit Kamudi, Sarimuddin, Nanik Suciati, Batik Image Classification Using SIFT Feature Extraction, Bag of Features and Support Vector Machine (2015). Procedia Computer Science, 72 (2015), 24-30. https://doi.org/10.1016/j.procs.2015.12.101

[6] F. S. Budiman, Adang Suhendra, Dewi Agushinta, Avinanta Tarigan (2016). Wavelet decomposition levels analysis for traditional Indonesia batik classification. Journal of Theoretical and Applied Information Technology, 92 (2016), no. 2, 389-394.

[7] BINUS BUSINESS REVIEW Vol. 3 No. 1 Mei 2012: $116-130$

[8] Imanuddin (2010). Batik Identification Based On Batik Pattern And Characteristics Using Fabric Pattern Feature Extraction. Jakarta: Gunadarma University.

[9] Rangkuti, Haris A. (2014). Klasifikasi Motif Batik Berbasis Kemiripan Ciri Dengan Wavelet Transform Dan Fuzzy Neural Network. Jakarta: ComTech Vol. 5 No. 1 Juni 2014: 361-372

[10] Riana, Dwiza dkk. (2013). Ekstraksi dan Klasifikasi Tekstur Citra Sel Nukleus Pap Smear. Bandung: Jurnal TICOM Vol.1 No.3 Mei 2013

[11] Sari, Jayanti Yusmah dkk. (2014). Similarity Based Entropy On Feature Selection For High Dimensional Data Classification. Surabaya: Journal of Computer Science and Information, Volume 7, Issue 2, June 2014 